\title{
Indicators and Determinants of Food Addiction among Fourth-grade Medical Students of Minia University in Egypt
}

\section{Marwa Gamal Abdelrehim.}

Department of Public Health, Preventive Medicine and Occupational Medicine, Faculty of Medicine, Minia University, El-Minia, Egypt.

Submission Date: 01-02-2021 Revision Date: 16-02-2021 Acceptance Date: 16-02-2021

\section{Abstract}

Background: Food addiction (FA) exists in one-sixth of Egyptian adolescents. It is associated with neuropsychiatric problems and is incriminated in the current obesity epidemic. Objectives: This study aimed to determine the prevalence of FA and its indicators among medical students of Minia University and to identify the predictors of FA indicators. Method: A cross-sectional survey of 394 medical students was conducted during November 2020. Students filled out a self-reported English questionnaire that included socio-demographics, smoking habits, modified Yale Food Addiction Scale 2 (mYFAS), Depression, Anxiety and Stress Scale-21 Items (DASS-21), and The General Practice Physical Activity Questionnaire (GPPAQ). Results: The prevalence of FA among the studied medical students was 11.4\% and $14.5 \%$ had three or more FA indicators. The most common FA indicator was craving $(24.9 \%)$ followed by withdrawal $(16.2 \%)$, use in physically hazardous situations $(15.2 \%)$, and unsuccessful quitting (14.7\%). The significant predictors of FA diagnosis were socioeconomic level, BMI, and depression. Most FA indicators were significantly associated with depression and/or stress. Furthermore, high BMI was associated with unsuccessful quitting, giving up or reduced activities, and interpersonal problems. Smoking correlated to loss of control, craving, and clinically significant impairment. The low socioeconomic level affected the withdrawal symptoms and interpersonal problems. Conclusion: FA indicators are common among medical students. Future studies should evaluate the impact of nutrition education and weight control combined with smoking cessation and psychological support to promote healthy eating behavior and reduce the rate of FA and obesity among medical students.

Keywords: Yale Food Addiction Scale, medical students, Depression, Anxiety and Stress Scale-21, cross-sectional study.

Corresponding author: Marwa Gamal Abdelrehim marwa.gamal@mu.edu.eg; marwagamal_84@yahoo.com

\section{Introduction}

With the rising prevalence of obesity and eating disorders around the world, ${ }^{1,2}$ food addiction (FA) has become a popular matter of debate. ${ }^{3}$ Repeated consumption of palatable foods mainly fats, sweets, a combination of fat/sugar, processed and/or high salt foods may trigger overeating by creating a long-term addiction-like effect on susceptible individuals. ${ }^{4-6}$ Similar patterns of neural activation are implicated in substance dependence with elevated activation in reward circuitry in response to food cues and reduced activation of inhibitory regions in response to food intake. ${ }^{7}$ There is a debate on the diagnosis of FA as a psychiatric disorder. As it has

Oct. 
been suggested that FA is a psychopathological phenomenon associated with anxiety or mood disorders, similar to substance-related, affective, and eating disorders, rather than independent psychiatric disease. ${ }^{3}$

FA exists among Egyptian adolescents who have a high prevalence of obesity as well. ${ }^{8}$ A previous study in Egypt showed that the prevalence of FA among adolescents was $15.7 \%$ and the most prevalent FA symptom was tolerance found in more than half of the sample. ${ }^{8}$ The prevalence of FA among university students ranged from $7.1 \%$ in nursing students as reported by Hong et al. $2020^{9}$ to $18.7 \%$ among different college students as reported by Coel et al. 2017. ${ }^{10}$ FA was expected to be higher among college students than high school students, ${ }^{11}$ because they face more stressful life events than adolescents. University students mostly became independents and/or left their parents' home for college. They are vulnerable to develop addictive behavior like problematic internet use, smoking, and poor eating habits with high consumption of affordable and delicious fast and processed foods ${ }^{12}$ with considerable addictive potential. ${ }^{5}$ They may suffer from depression due to the stress of academic requirements, time pressure, and social adjustments. $^{13}$ Medical students, in particular, may face additional pressures such as the large workload, the medical curriculum, time commitment, number of assessments, and stress of clinical environment that contribute to their higher rates of depression compared to other college students of similar age. ${ }^{14-16}$

FA is previously correlated with higher BMI and tobacco smoking. It is a complex behavior associated with other psychiatric disorders, like depression, stress, anxiety, and sleeping problems so it may lead to dangerous health effects. ${ }^{17}$ Therefore, FA problem should be targeted with the efforts towards reducing food-related problems involving obesity. ${ }^{6}$ Screening for FA and its indicators among medical students offers the opportunity for early risk identification, nutrition education to enhance healthy eating behaviors and prevent eating disorders and obesity, besides, management of the affected subjects. ${ }^{18}$

A recent review of $F A$ as measured with the Yale Food Addiction Scale (YFAS) concluded that the criteria for FA need more research. Studies should assess the individual items of the scale rather than using its cut-off criteria to examine the underlying mechanisms of this behavior from a clinical perspective. ${ }^{19}$ Another study has found that nutrition education on FA induced reduction in the rates of FA diagnosis and slight improvements in FA markers after the program. ${ }^{18}$ Given the high prevalence of FA behavior in the literature, there is a warrant for continued research on the biological, psychological, and social factors that contribute to addiction symptoms in the preceding stages of FA to facilitate the development of early interventions. Also, it is important to promote healthy eating behaviors among medical students who aspire to care for others' health. This study aims to identify the prevalence of FA indicators and their determinants including socioeconomic state, physical activity level, and mental health problems among medical students of Minia University. Previous studies reported that medical students in the preclinical (first three) years were under higher emotional distress and had higher rates of depression, anxiety, and stress than older students in the clinical years. $^{20,21}$ In addition, extra stress and tension may be present due to the newly introduced integrated system of teaching in Minia University that may affect their

Oct. 
response in the study. Stress significantly decreased as the year of study increased, except for the final year. ${ }^{21}$ Therefore, the study included fourth-grade students to represent the middle year in the faculty.

\section{Method}

Study design and participants: This crosssectional study was carried out among fourth-year medical students in the Faculty of Medicine, Minia University during November 2020. G*Power 3.1 program (Faul et al.) ${ }^{22}$ was used to determine the appropriate sample size. A previous study reported that the prevalence of FA among Egyptian adolescents was about 15\% that was used for testing the power. ${ }^{8}$ For logistic regression, to detect a moderate effect size of 1.5 using a two-tailed test, and to maintain a significance level of 0.05 and a statistical power of 0.80 , the required sample size was calculated to be 378 . All fourth-year medical students were invited to participate in the study to compensate for lack of response or incomplete data. Then 450 questionnaires were filled and returned with $90 \%$ response rate and the final sample included in the study were 394 after excluding the incomplete questionnaires.

Data collection and measures: The participating students were requested to fill a paper English version of the questionnaire under the supervision of demonstrators of public health who explained in advance the purpose and methods of the study and their right to decline to participate. The questionnaire included (1) Demographic data, including age, sex, residence and marital state, and smoking history. Smoking was defined according to the standard National Health Interview Survey (NHIS) current smoking definition. Smoker is an adult who currently smokes cigarettes and has smoked 100 cigarettes in his/her lifetime. ${ }^{23}$
(2) The socioeconomic scale (SES) of ElGilany et al. 2012 which is a valid and reliable scale to assess family socioeconomic status consisting of 7 domains (education and occupation of mother and father, family domain, family possessions, home sanitation, health care, and economic domains) with a total score of 84 (a higher score indicating better socioeconomic status). The socioeconomic levels are classified depending on the quartiles of the calculated score into very low (0-21), low (22-42), middle (43-63), and high (64-84). ${ }^{24}$

(3) The Modified Yale Food Addiction Scale (mYFAS 2.0) is a validated tool ${ }^{25}$ that was used to assess FA diagnosis and detect the presence of FA indictors. The measure consists of 13 self-report questions that assess 11 substance use disorder criteria of the Diagnostic and statistical manual of mental disorders $(\mathrm{DSM}-5)^{26}$ plus clinically significant impairment/distress (assessed by two questions) representing $12 \mathrm{FA}$ indicators. Each FA symptom or indicator is given a score according to the response to each question ranging from never $(0)$ to everyday (7). Each question has a threshold, if the score for the symptom reach the threshold, then the FA indicator criterion has been met. Moreover, FA diagnosis was established if the symptom count is 2 or more plus clinically significant impairment/distress. The scale items included: larger amounts consumed and for longer periods; repeated unsuccessful attempts to quit; too much time to obtain, use, or recover; giving up social, occupational, or entertaining activities to eat; continual use despite adverse consequences; tolerance to food; withdrawal symptoms; continued use despite social/interpersonal problems; inability to fulfill main role obligation (e.g., work, school, home); use in 
Table (1): Characteristics of the studied medical students according to FA diagnosis

\begin{tabular}{|c|c|c|c|c|c|}
\hline & & & & FA & \\
\hline Chara & teristics & $\begin{array}{l}N=394 \\
N(\%)\end{array}$ & $\begin{array}{c}\text { Yes } \\
\mathrm{N}=45 \\
\mathrm{~N}(\%)\end{array}$ & $\begin{array}{c}\text { No } \\
\text { N=349 } \\
\text { N (\%) }\end{array}$ & p-value \\
\hline Age (mean \pm SD) & & $21.6 \pm 1.05$ & $21.5 \pm 1.2$ & $21.6 \pm 1.0$ & 0.662 \\
\hline Sex & Male & $145(36.8)$ & $20(44.4)$ & $125(35.8)$ & \\
\hline & Female & $249(63.2)$ & $25(55.6)$ & $224(64.2)$ & 0.259 \\
\hline Marital state & Unmarried & $378(95.9)$ & $43(95.6)$ & $335(96)$ & \\
\hline & Married & $16(4.1 \%)$ & $2(4.4)$ & $14(4)$ & 0.890 \\
\hline Residence & Rural & $212(53.8)$ & $23(51.1)$ & $189(54.2)$ & \\
\hline & Urban & $182(46.2)$ & $22(48.9)$ & $160(45.8)$ & 0.700 \\
\hline Socio-economic level & Very low & $99(25.1)$ & $14(31.1)$ & $85(24.4)$ & \\
\hline & Low & $98(24.9)$ & $17(37.8)$ & $81(23.2)$ & \\
\hline & Middle & $98(24.9)$ & $3(6.7)$ & $95(27.2)$ & \\
\hline & High & $99(25.1)$ & $11(24.4)$ & $88(25.2)$ & 0.012 \\
\hline Smoking & Non-smoker & $345(87.6)$ & $37(82.2)$ & $308(88.3)$ & \\
\hline & Smoker & $49(12.4)$ & $8(17.8)$ & $41(11.7)$ & 0.249 \\
\hline Physical activity & Inactive & $30(7.6)$ & $6(13.3)$ & $24(6.9)$ & \\
\hline & Moderate active & $163(41.4)$ & $21(46.7)$ & $142(40.7)$ & \\
\hline & Active & $201(51)$ & $18(40)$ & $183(52.4)$ & 0.155 \\
\hline BMI & $18.5-24.9$ & $258(65.5)$ & $22(48.9)$ & $236(67.6)$ & \\
\hline & $25-29.9$ & $110(27.9)$ & $17(37.8)$ & $93(26.6)$ & \\
\hline & $\geq 30$ & $26(6.6)$ & $6(13.3)$ & $20(5.8)$ & 0.025 \\
\hline DASS-21 dimensions & & & & & \\
\hline Depression (total scor & & $20.6 \pm 1.05$ & $8.7 \pm 4.9$ & $5.6 \pm 4.3$ & \\
\hline & Normal & $167(42.4)$ & $10(22.2)$ & $157(45)$ & 0.000 \\
\hline & Mild & $70(17.8)$ & $4(8.9)$ & $66(18.9)$ & \\
\hline & Moderate & $102(25.9)$ & $18(40)$ & $84(24.1)$ & \\
\hline & Severe & $30(7.6)$ & $7(15.6)$ & $23(6.6)$ & 0.001 \\
\hline & Extremely severe & $25(6.3)$ & $6(13.3)$ & $19(5.4)$ & \\
\hline Anxiety (total score) & & $20.6 \pm 1.05$ & $8.2 \pm 4.9$ & $5.5 \pm 3.8$ & 0.000 \\
\hline & Normal & $124(31.5)$ & $9(20)$ & $115(33)$ & \\
\hline & Mild & $43(10.9)$ & $1(2.2)$ & $42(12)$ & \\
\hline & Moderate & $106(26.9)$ & $13(28.9)$ & $93(26.6)$ & 0.002 \\
\hline & Severe & $51(12.9)$ & $5(11.1)$ & $46(13.2)$ & \\
\hline & Extremely severe & $70(17.8)$ & $17(37.8)$ & $53(15.2)$ & \\
\hline Stress (total score) & & $20.6 \pm 1.05$ & $9.2 \pm 4.3$ & $6.8 \pm 4.2$ & 0.000 \\
\hline & Normal & $222(56.3)$ & $18(40)$ & $204(58.5)$ & \\
\hline & Mild & $62(15.7)$ & $6(13.4)$ & $56(16)$ & \\
\hline & Moderate & $67(17)$ & $11(24.4)$ & $56(16)$ & 0.028 \\
\hline & Severe & $37(9.5)$ & $8(17.8)$ & $29(8.3)$ & 0.028 \\
\hline & Extremely severe & $6(1.5)$ & $2(4.4)$ & $4(1.2)$ & \\
\hline
\end{tabular}

physically hazardous situations (i.e. distraction by eating so that the subject may be hurt as when driving a car, crossing the street, operating machinery); and craving. Additionally, clinically significant impairment/distress was present if eating behavior caused a lot of distress and if there were significant problems in life because of food and eating. ${ }^{25}$ (4) The General Practice Physical Activity Questionnaire (GPPAQ) ${ }^{27}$ was included to calculate the four-level Physical activity index (PAI) which is a valid tool ${ }^{28}$ to classify the participants into four categories:

Oct. 


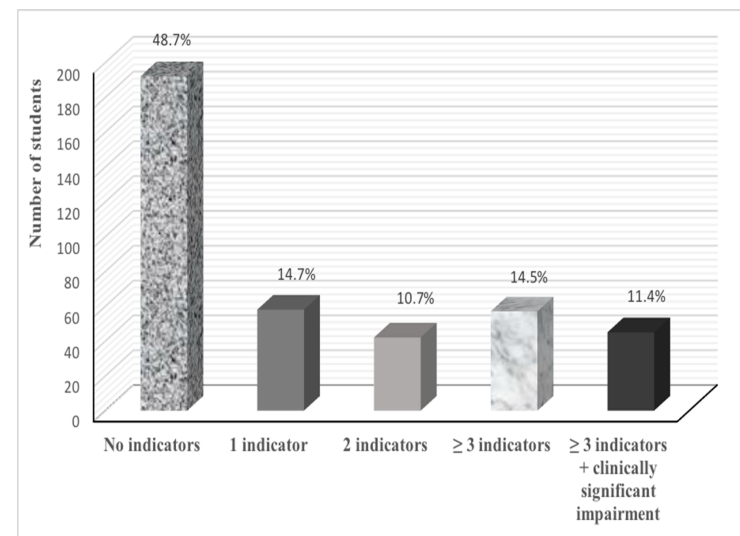

Figure (1): The number and percentage of students according to the number of reported FA indicators

1) Inactive if unemployed or having a sedentary job with no physical exercise/cycling. 2) Moderately inactive if unemployed or having a sedentary job with $<1$ hour physical exercise/cycling per week or standing job with no physical exercise/cycling. 3) Moderately active if unemployed or having a sedentary job with 1-2.9 hours physical exercise/cycling per week or standing job with $<1$ hour physical exercise/cycling per week or physical job with no physical exercise/cycling 4) Active if unemployed or having a sedentary job with $\geq 3$ hours physical exercise/cycling per week or having a standing job with 12.9 hours physical exercise/cycling per week or having a physical job with $<1$ hour physical exercise/cycling per week or having a heavy manual job.

(5) Depression, Anxiety, and Stress Scale21 Items (DASS-21) to evaluate the mental health problems of depression, anxiety, and stress during the past month. This scale includes three sub-scales (each one has 7 items): (1) Depression sub-scale which evaluates hopelessness, selfdeprecation, little self-esteem, lack of interest, and low positive effect; (2) Anxiety sub-scale which assesses autonomic arousal, situational anxiety, skeletal muscle effects, and subjective experience of anxious factors; and (3)

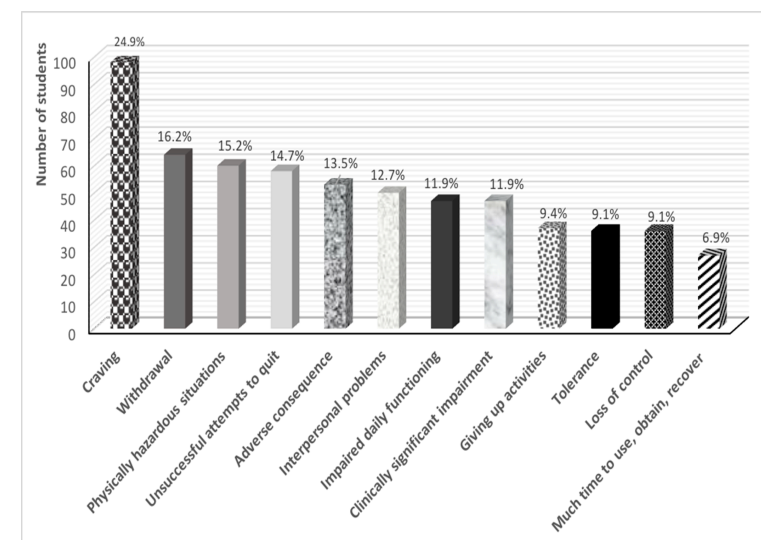

Figure (2): Prevalence of FA indicators among the studied medical students

Stress sub-scale which measures difficulty relaxing, irritability, nervous arousal, agitation, and impatience. The scale has 21 statements, and each participant should indicate how much the statement applied to him/her over the past month using a scale ranged from 0 (did not apply at all) to 3 (applied very much or most of the time). Scores of the subscales are calculated by summing the scores for the relevant items then multiplied by 2 to calculate the final score. Different degrees of emotional disorder were assigned according to the recommended cut-off scores for conventional severity labels. Depression was classified to normal (0-9), mild (1013), moderate (14-20), severe (21-27), and extremely severe $(\geq 28)$. Anxiety had normal (0-7), mild (8-9), moderate (10-14), severe (15-19) and extremely severe $(\geq 20)$ degrees. Stress levels included normal (014), mild (15-18), moderate (19-25), severe (26-33) and extremely severe $(\geq 34){ }^{29,} 30$

(6) Measuring the weight and height to calculate BMI as weight $(\mathrm{kg}) /$ height $(\mathrm{m})^{2}$. Participants were classified according to BMI into normal weight (18.5-24.9), overweight (25-29.9), and obese ( $\geq 30)$.

A pilot study was conducted among 30 participants to assess the feasibility of the study and problems with the questionnaire. Both mYFAS2 and DASS-21 showed high

Oct. 
Table (2): Determinants of FA indicators among the studied medical students

\begin{tabular}{|c|c|c|c|c|}
\hline \multirow{2}{*}{$\begin{array}{l}\text { Indicators of FA } \\
\text { Loss of control }\end{array}$} & \multirow{2}{*}{$\begin{array}{l}\text { Predictors } \\
\text { Smoking }\end{array}$} & \multicolumn{2}{|c|}{ Adjusted OR (95\% CI) } & \multirow{2}{*}{$\begin{array}{l}\text { p-value } \\
0.016\end{array}$} \\
\hline & & & $2.84(1.20-6.65)$ & \\
\hline & Depression & & $2.00(1.00-4.37)$ & 0.044 \\
\hline & Stress & & $2.23(1.03-4.82)$ & 0.041 \\
\hline \multirow[t]{5}{*}{ Unsuccessful attempts to quit } & BMI & Normal & 1 & \\
\hline & & Overweight & $2.53(1.34-4.77)$ & 0.004 \\
\hline & & Obese & $5.51(2.16-14.04)$ & 0.000 \\
\hline & Depression & & $2.19(1.16-4.14)$ & 0.015 \\
\hline & Stress & & $2.16(1.15-4.08)$ & 0.017 \\
\hline Much time to obtain, use, recover & Anxiety & & $3.48(1.29-9.38)$ & 0.014 \\
\hline \multirow[t]{4}{*}{ Giving up or reduced activities } & BMI & Normal & 1 & \\
\hline & & Overweight & $2.17(1.01-4.72)$ & 0.050 \\
\hline & & Obese & $6.12(2.24-16.70)$ & 0.000 \\
\hline & Depression & & $2.71(1.32-5.60)$ & 0.007 \\
\hline \multirow[t]{2}{*}{ Adverse consequences } & Depression & & $2.96(1.53-5.71)$ & 0.001 \\
\hline & Stress & & $2.19(1.16-4.15)$ & 0.016 \\
\hline \multirow[t]{4}{*}{ Tolerance } & Age & & $0.46(0.31-0.68)$ & 0.000 \\
\hline & Sex (male) & & $2.30(1.04-5.07)$ & 0.040 \\
\hline & Depression & & $2.69(1.19-6.08)$ & 0.017 \\
\hline & Stress & & $4.59(2.07-10.19)$ & 0.000 \\
\hline \multirow[t]{5}{*}{ Withdrawal } & Socioeconomic & Very low & 1 & \\
\hline & & Low & $0.96(0.48-1.92)$ & 0.906 \\
\hline & & Middle & $0.30(0.12-0.73)$ & 0.008 \\
\hline & & High & $0.61(0.28-1.33)$ & 0.215 \\
\hline & Anxiety & & $3.85(1.96-7.55)$ & 0.000 \\
\hline \multirow[t]{9}{*}{ Interpersonal problems } & BMI & Normal & 1 & \\
\hline & & Overweight & $1.48(0.70-3.13)$ & 0.304 \\
\hline & & Obese & $9.43(3.49-25.47)$ & 0.000 \\
\hline & Socioeconomic & Very low & 1 & \\
\hline & & Low & $0.28(0.11-0.72)$ & 0.008 \\
\hline & & Middle & $0.24(0.09-0.64)$ & 0.004 \\
\hline & & High & $0.49(0.21-1.15)$ & 0.102 \\
\hline & Depression & & $4.33(2.03-9.23)$ & 0.000 \\
\hline & Stress & & $2.11(1.04-4.28)$ & 0.038 \\
\hline \multirow[t]{2}{*}{ Impaired daily functioning } & Depression & & $2.11(1.08-4.14)$ & 0.030 \\
\hline & Stress & & $2.17(1.11-4.23)$ & 0.023 \\
\hline \multirow[t]{3}{*}{ Use in physically hazardous situations } & Sex (male) & & $2.27(1.26-4.09)$ & 0.006 \\
\hline & Stress & & $2.80(1.51-5.20)$ & 0.001 \\
\hline & Anxiety & & $2.41(1.18-4.91)$ & 0.015 \\
\hline \multirow[t]{2}{*}{ Craving } & Smoking & & $2.00(1.26-3.19)$ & 0.003 \\
\hline & Depression & & $2.04(1.07-3.88)$ & 0.030 \\
\hline \multirow{2}{*}{$\begin{array}{l}\text { Clinically significant } \\
\text { impairment }\end{array}$} & Smoking & & $2.79(1.28-6.11)$ & 0.010 \\
\hline & Depression & & $3.24(1.70-6.17)$ & 0.000 \\
\hline
\end{tabular}

* Depression, anxiety, and stress were used as binary variables.

internal consistency (Cronbach's alpha to sociodemographic variables and value $>0.70$ ).

\section{Statistical analysis}

IBM SPSS version 25.0 was used for statistical analyses. The significance level was $\alpha=0.05$.

The prevalence of FA diagnosis and indicators of FA were identified in relation emotional problems. Continuous variables were compared using the independentsample t-test. Categorical variables were compared using Pearson's chi-square test or Fisher's exact test, as appropriate. Binary logistic regression was used to assess the associations between each

Oct. 
indicator of FA and sociodemographic characteristics, physical activity level, and emotional problems. Significant factors were included in the multivariate model to calculate the adjusted odds ratios (AOR) and $95 \%$ confidence intervals $(\mathrm{CI})$.

\section{Ethical consideration}

The study was approved by the ethical research committee of the Faculty of Medicine, Minia University. Verbal assent was obtained from the participating students before completing the study questionnaires.

\section{Results}

The current study included 394 medical students in Minia University, 145 (36.8\%) males and $249(63.2 \%)$ females, aged $21.6 \pm 1.5$ years old (range, 20-23 years). Among the participating students, $11.4 \%$ satisfied the criteria for diagnosis with FA, $57.6 \%$ had depressive symptoms, $68.5 \%$ had anxiety, and $43.7 \%$ suffered from stress. The demographic and psychological characteristics of the studied students in relation to FA diagnosis were presented in Table 1. FA was significantly associated with the socioeconomic level, BMI, and mental health problems including depression, anxiety, and stress. Food addicted students had a lower socioeconomic level $(\mathrm{p}=0.012)$, higher BMI $(p=0.025)$ and higher levels of depression $(p=0.001)$, anxiety $(p=0.002)$ and stress $(\mathrm{p}=0.028)$. No significant differences in age, sex, marital state, residence, smoking, and physical activity were found between the two groups (Table 1). The multivariable logistic analysis showed that the significant predictors of FA behavior were socioeconomic level (AOR of middle versus very low level, 0.14; 95\% CI: 0.05-0.53), BMI (AOR of obese versus normal BMI, 3.52; 95\% CI: 1.20-10.28), and depression (AOR, 2.85;
95\% CI: 1.34-6.06) (This data was not shown in tables).

Figure 1 showed that $14.7 \%$ of the studied medical students had one FA indicator, $10.7 \%$ had two, $14.5 \%$ had three or more, and $11.4 \%$ met the criteria for FA diagnosis. The most prevalent FA indicator was craving found in $98(24.9 \%)$ students followed by withdrawal in $64(16.2 \%)$, use in physically hazardous situations in 60 $(15.2 \%)$, and unsuccessful quitting in 58 (14.7\%) students as shown in Figure 2.

Results of multivariable logistic regression of FA indicators and sociodemographic and psychosocial correlates were shown in Table 2. Most symptoms of FA were significantly associated with depression and/or stress. Socioeconomic level significantly affected withdrawal symptoms and interpersonal problems. Smoking was associated with loss of control, craving, and clinically significant impairment. BMI was associated with unsuccessful attempts to quit, giving up/reduced activities, and interpersonal problems.

\section{Discussion}

The current study found that $11.4 \%$ of the studied medical students were meeting criteria for FA and $14.7 \%$ had $\geq 3$ symptoms of FA. The prevalence of FA among college students varies in the literature from $7.1 \%$ to $18.7 \%{ }^{9-11,17,31,32}$ While, studies evaluating FA in the general population and among obese subjects showed higher prevalence rates (19.9\% and $38 \%$ respectively). ${ }^{33}, 34$ The most common FA indicators or in our study were craving $(24.9 \%)$ followed by withdrawal (16.2\%) and use in physically hazardous situations (15\%). Craving is the typical phenomenon of addiction and with ceasing consumption of certain foods the subject suffers from withdrawal symptoms and control is lost. However, there are 
different reported rates of the predominant FA indicators among adolescents ${ }^{8}$ and university students ${ }^{9}$ which may be due to differences in the sociocultural factors, education level, or associated behavioral problems. Generally, FA and its indicators are common among medical students who may have irregular lifestyle during involvement in lectures, clinical training, and skill development. Therefore, it is important to identify the predictors of the early indicators of addiction in the preliminary stages of FA to facilitate the development of early interventions.

Medical students usually suffer from stress during the medical education which may decrease their academic achievement and increase their risk of developing depression. $^{35}$ The current study reported that the rates of depression, anxiety, and stress among medical students of Minia University were $57.6 \%, 68.5 \%$, and $43.7 \%$ respectively. While the percentages reported by Fawzy et al. 2017 whose study included medical students of Assiut University were $65 \%, 73 \%$, and $59.9 \%$ respectively. ${ }^{20}$ High levels of depression symptoms (83.4\%) were also found among Saudi medical students as reported by Alharbi et al. 2018. ${ }^{36}$ Globally, depression among medical students was highest in Africa $(40.9 \%)^{16}$ and anxiety was most prevalent in the Middle East and Asia. ${ }^{15}$ On the other hand, Brazilian medical students had lower rates of depression, anxiety, and stress $(30.6 \%, 32.9 \%$, and $49.9 \%$ respectively) as reported by Pacheco et al., 2017. ${ }^{37}$ Furthermore, the worldwide prevalence of depression and anxiety in medical students were $27 \%$ and $33.8 \%$ respectively. ${ }^{15}, 16$ These findings indicate that there are relatively higher rates of depression among medical students in Egypt and Saudi Arabia than in western countries which may be due to cultural and social factors that imply more pressure on medical students who must be excellent in all aspects of life. Also, lack of early diagnosis and effective treatment may lead to increased symptoms overtime because depression in medical students is accumulative. $^{38}$

Numerous findings among college students indicated that females were at greater risk of $\mathrm{FA}^{10,11,19,31-33}$ and scored higher in most dimensions of YFAS than male students. ${ }^{39}$ However, the present study and some prior research ${ }^{17,} 40,41$ found no significant relation of gender with FA and male students were more likely presented with tolerance and using food in physically hazardous situations than females. Such inconsistencies may exist because the samples from several studies were predominantly women ${ }^{31,33} 19$ and there may be an overlap of FA diagnosis with other conditions as bulimia and anorexia nervosa which are more predominant in women than men. ${ }^{42}$ Moreover, a recent study confirmed that the effect of sex on the YFAS score did not remain after controlling for anxiety and perceived stress. $^{43}$

Consistent with the literature, ${ }^{10,17,19,31-}$ $33,44,45$ the present study found that obese students were more likely to have FA than healthy weight participants. Moreover, obesity was significantly associated with unsuccessful attempts to quit, giving up/reduced activities, and interpersonal problems which support the findings of a previous study among Egyptian adolescents. ${ }^{8}$ On the other side, some studies failed to reveal any significant relationships between the total YFAS score and BMI. ${ }^{8,}{ }^{41}$ Since FA refers to repeated compulsive consumption of certain highly palatable foods, ${ }^{44}$ it consequently can lead to overweight and obesity. ${ }^{45}$ On the other side, people with higher BMI have higher frequencies of food cravings. ${ }^{46}$ Moreover, there may be biological and hormonal

Oct. 
factors associated with both the body weight and the risk of FA. ${ }^{47}$

This study found that a higher socioeconomic level was significantly associated with lower FA risk, fewer withdrawal symptoms, and fewer interpersonal/social problems. A previous study indicated that diet quality follows a socioeconomic gradient. Whereas energydense foods which are usually poor in nutrients, having addictive potential, easy physical access, and low cost are preferentially consumed by persons of lower socioeconomic level. ${ }^{48}$ A detailed study of the social factors associated with FA symptoms will allow for further evaluation of contributors to FA among medical students and young adults in general.

The current study's result is consistent with the literature, found that depression was a significant predictor of FA diagnosis among medical students and most FA indicators were significantly associated with depression and/or stress. Evidence has generally shown that mental health problems specifically depression, anxiety, and stress were significantly associated with FA. ${ }^{9,} 49,50$ Whereas, medical students are frequently under stress and have a high rate of depression, ${ }^{16}$ they are prone to FA symptoms. Depression has been shown to alter food preferences, induce the overconsumption of energy-dense foods, and increase the risk of abdominal obesity. $^{51}$

Although smoking was not a predictor for FA in the current results, it was significantly associated with loss of control, craving, and clinically significant impairment. Cigarette smoking was previously considered as an appetite suppressant, however, the physiological effect of smoking on body weight was slight and smokers had higher risks of abdominal obesity. ${ }^{52}$ Several studies reported that smoking is a risk factor that can trigger $\mathrm{FA}^{17,53}$ and was associated with high frequencies of food cravings specifically high-fat foods. ${ }^{54,}{ }^{55}$ Other findings concluded that each of nicotine use and highly palatable foods stimulate the pathways responsible for reward and contribute to the development of addiction. ${ }^{56} \mathrm{FA}$ and tobacco use disorder share similar but not identical neurological, physiological, and behavioral abnormalities. ${ }^{57}$ However, further research has to examine the relationship between smoking and FA and the advantage of smoking cessation on the prevalence of FA symptoms among students.

To our knowledge, this is the first study that reports the prevalence of FA and its indicators among the medical students in Egypt and Arab countries. The strengths of this study included the use of the standardized YFAS and DASS-21 which allows comparisons with results from other countries and cultures. Furthermore, the study included the evaluation of several potential confounding factors such as age, sex, socioeconomic state, smoking, physical activity level, and mental health problems. However, the study had some weaknesses. First, the cross-sectional design did not allow for the identification of directionality between FA indicators and the predictors. Second, the use of selfreported data may affect the validity and reliability of estimates. Self-reporting of mental health symptoms and smoking status may underestimate the true rates, so there may be a potential for misclassification bias. Finally, the study included students from one grade and one university, which renders it difficult to generalize the current results to all medical students.

\section{Conclusion}


In conclusion, the rate of FA among medical students was $11.4 \%$ and was predicted by obesity, depression, and low socioeconomic level. Most FA indicators were significantly associated with depression and/or stress. Furthermore, high BMI, smoking, and low socioeconomic level also affected some of FA indicators. Future studies should evaluate the effects of nutrition education and weight management programs combined with smoking cessation, psychological counseling, and effective mental health interventions to reduce the rate of FA and obesity among medical students.

\section{Acknowledgments}

The author would like to acknowledge each of Shaza Alkilany, Nermen Dahi, and Sarah Mohamed, demonstrators of public health, for their efforts in communication with the students and data collection.

Funding: No funding was received for this study.

Conflicts of Interest: There is no conflict of interest.

References

1. World Health Organization (WHO). Obesity and overweight [updated 2020 April 1; cited 2021 January 15]. Avialable from: https://www.who.int/news-room/factsheets/detail/obesity-and-overweight

2. Galmiche M, Dechelotte P, Lambert G, Tavolacci MP. Prevalence of eating disorders over the 2000-2018 period: a systematic literature review. Am J Clin Nutr. 2019;109(5):1402-13.

doi:10.1093/ajen/nqy342.

3. Piccinni A, Bucchi R, Fini C, Vanelli F, Mauri M, Stallone T, et al. Food addiction and psychiatric comorbidities: a review of current evidence. Eat Weight Disord. 2020. doi:10.1007/s40519-020-01021-3.

4. Corsica JA, Pelchat ML. Food addiction: true or false? Curr Opin Gastroenterol. 2010;26(2):165-9.

doi:10.1097/MOG.0b013e328336528d.

5. Schulte EM, Avena NM, Gearhardt AN. Which foods may be addictive? The roles of processing, fat content, and glycemic load. PLoS One. 2015;10(2):e0117959.

6. Ayaz A, Nergiz-Unal R, Dedebayraktar D, Akyol A, Pekcan AG, Besler HT, et al. How does food addiction influence dietary intake profile? PLoS One. 2018;13(4):e0195541. doi:10.1371/journal.pone.0195541.

7. Gearhardt AN, Yokum S, Orr PT, Stice E, Corbin WR, Brownell KD. Neural correlates of food addiction. Arch Gen Psychiatry. 2011;68(8):808-16.

doi:10.1001/archgenpsychiatry.2011.32.

8. Ahmed AY, Sayed AM. Prevalence of food addiction and its relationship to body mass index. Egyptian Journal of Medical Human Genetics. 2017;18(3):257-60. doi:10.1016/j.ejmhg.2016.10.002.

9. Hong HJ, Kim R, Kim AS, Kim JH, Kim HJ, Song JH, et al. Correlations Between Stress, Depression, Body Mass Index, and Food Addiction Among Korean Nursing Students. J Addict Nurs. 2020;31(4):236-42. doi:10.1097/JAN.0000000000000362.

10.Coel ML, Maier H, Spicer M, Kearley M. Prevalence of and Risk Factors for Food Addiction Among University Students. 2017.

11.Borisenkov MF, Popov SV, Pecherkina AA, Dorogina OI, Martinson EA, Vetosheva VI, et al. Food addiction in young adult residents of Russia: Associations with emotional and anthropometric characteristics. Eur Eat Disord Rev. 2020;28(4):465-72. doi:10.1002/erv. 2731.

12.Gündüz N, Gökçen O, Eren F, Erzincan E, Timur Ö, Turan $\mathrm{H}$, et al. The relationship between internet addiction and eating attitudes and obesity related problems among university students. Turkish J Clinical Psychiatry. 2019;22:266-75.

13.Akhtar P, Ma L, Waqas A, Naveed S, Li Y, Rahman A, et al. Prevalence of depression among university students in low and middle income countries (LMICs): a systematic review and meta-analysis. J Affect Disord. 2020;274:911-9.

doi:10.1016/j.jad.2020.03.183.

14. Moir F, Yielder J, Sanson J, Chen Y. Depression in medical students: current insights. Adv Med Educ Pract. 2018;9:323-33. doi:10.2147/AMEP.S137384. 
15.Quek TT, Tam WW, Tran BX, Zhang M, Zhang Z, Ho CS, et al. The Global Prevalence of Anxiety Among Medical Students: A MetaAnalysis. Int J Environ Res Public Health. 2019;16(15):2735. doi:10.3390/ijerph16152735.

16.Tam W, Lo K, Pacheco J. Prevalence of depressive symptoms among medical students: overview of systematic reviews. Med Educ. 2019;53(4):345-54.

17.Najem J, Saber M, Aoun C, El Osta N, Papazian T, Rabbaa Khabbaz L. Prevalence of food addiction and association with stress, sleep quality and chronotype: A crosssectional survey among university students. Clin Nutr. 2020;39(2):533-9. doi:10.1016/j.clnu.2019.02.038.

18.Lewis SL, Anderson ME, Pobocik RS, Ludy M. The Impact of Nutrition Education on Food Addiction among College Students. J Acad Nutr Diet. 2015;115(9):A31. doi:10.1016/j.jand.2015.06.106.

19.Penzenstadler L, Soares C, Karila L, Khazaal Y. Systematic Review of Food Addiction as Measured with the Yale Food Addiction Scale: Implications for the Food Addiction Construct. Curr Neuropharmacol. 2019;17(6):526-38.

doi:10.2174/1570159X16666181108093520.

20.Fawzy M, Hamed SA. Prevalence of psychological stress, depression and anxiety among medical students in Egypt. Psychiatry Res. 2017;255:186-94. doi:10.1016/j.psychres.2017.05.027.

21.Abdulghani HM, AlKanhal AA, Mahmoud ES, Ponnamperuma GG, Alfaris EA. Stress and its effects on medical students: a crosssectional study at a college of medicine in Saudi Arabia. J Health Popul Nutr. 2011;29(5):516. doi: 10.3329/jhpn.v29i5.8906 22.Faul F, Erdfelder E, Lang A-G, Buchner A. G*Power 3: A flexible statistical power analysis program for the social, behavioral, and biomedical sciences. Behav Res Methods. 2007;39(2):175-91. doi:10.3758/BF03193146.

23.Centers for Disease Control and Prevention NCfHS. The National Health Interview Survey (NHIS): Adult Tobacco Use Information. Avialable from: https://www.cdc.gov/nchs/nhis/tobacco.htm.
24.El-Gilany A, El-Wehady A, El-Wasify M. Updating and validation of the socioeconomic status scale for health research in Egypt. East Mediterr Health J. 2012;18(9):962-8. doi:10.26719/2012.18.9.962.

25. Schulte EM, Gearhardt AN. Development of the Modified Yale Food Addiction Scale Version 2.0. Eur Eat Disord Rev. 2017;25(4):302-8. doi:10.1002/erv.2515.

26. American Psychiatric Association. Diagnostic and statistical manual of mental disorders (DSM-5®): American Psychiatric Pub; 2013.

27.National Collaborating Centre for Nursing and Supportive Care (UK). Irritable Bowel Syndrome in Adults: Diagnosis and Management of Irritable Bowel Syndrome in Primary Care [Internet]. (NICE Clinical Guidelines, No. 61.) Appendix J, The General Practice Physical Activity Questionnaire (GPPAQ). Avialable from: https://www.ncbi.nlm.nih.gov/books/NBK519 $62 /$

28. Wareham NJ, Jakes RW, Rennie KL, Schuit J, Mitchell J, Hennings S, et al. Validity and repeatability of a simple index derived from the short physical activity questionnaire used in the European Prospective Investigation into Cancer and Nutrition (EPIC) study. Public Health Nutr. 2003;6(4):407-13.

29.Lovibond SH, Lovibond PF. Manual for the depression anxiety stress scales. Sydney: Psychology Foundation of Australia; 1995.

30.Henry JD, Crawford JR. The short-form version of the Depression Anxiety Stress Scales (DASS-21): construct validity and normative data in a large non-clinical sample. Br J Clin Psychol. 2005;44(Pt 2):227-39. doi:10.1348/014466505X29657.

31.Obregon A, Fuentes J, Pettinelli P. Association between food addiction and nutritional status in Chilean college students. Rev Med Chil. 2015;143(5):589. doi:10.4067/S0034-98872015000500006.

32.Yu Z, Tan M. Disordered Eating Behaviors and Food Addiction among Nutrition Major College Students. Nutrients. 2016;8(11):673. doi:10.3390/nu8110673.

33.Pursey KM, Stanwell P, Gearhardt AN, Collins CE, Burrows TL. The prevalence of 
food addiction as assessed by the Yale Food Addiction Scale: a systematic review. Nutrients. 2014;6(10):4552-90. doi:10.3390/nu6104552.

34. Meule A, Hermann T, Kubler A. Food addiction in overweight and obese adolescents seeking weight-loss treatment. Eur Eat Disord Rev. 2015;23(3):193-8. doi:10.1002/erv.2355. 35.Haldorsen H, Bak NH, Dissing A, Petersson B. Stress and symptoms of depression among medical students at the University of Copenhagen. Scandinavian journal of public health. 2014;42(1):89-95. doi: $10.1177 / 1403494813503055$.

36.Alharbi H, Almalki A, Alabdan F, Haddad B. Depression among medical students in Saudi medical colleges: a cross-sectional study. Adv Med Educ Pract. 2018;9:887-91. doi:10.2147/AMEP.S182960.

37.Pacheco JP, Giacomin HT, Tam WW, Ribeiro TB, Arab C, Bezerra IM, et al. Mental health problems among medical students in Brazil: a systematic review and meta-analysis. Brazilian Journal of Psychiatry. 2017;39(4):369-78.

38.Ludwig AB, Burton W, Weingarten J, Milan F, Myers DC, Kligler B. Depression and stress amongst undergraduate medical students. BMC Med Educ. 2015;15(1):141. doi:10.1186/s12909-015-0425-z.

39.Carr MM, Catak PD, Pejsa-Reitz MC, Saules KK, Gearhardt AN. Measurement invariance of the Yale Food Addiction Scale 2.0 across gender and racial groups. Psychol Assess. 2017;29(8):1044-52. doi:10.1037/pas0000403.

40. Meadows A, Nolan LJ, Higgs S. Selfperceived food addiction: Prevalence, predictors, and prognosis. Appetite. 2017;114:282-98. doi:10.1016/j.appet.2017.03.051. 41.Grammatikopoulou MG, Gkiouras K, Markaki A, Theodoridis X, Tsakiri V, Mavridis $\mathrm{P}$, et al. Food addiction, orthorexia, and food-related stress among dietetics students. Eating and Weight Disorders-Studies on Anorexia, Bulimia and Obesity. 2018;23(4):459-67. doi:10.1007/s40519-0180514-1.
42.Meule A, Gearhardt AN. Ten Years of the Yale Food Addiction Scale: a Review of Version 2.0. Current Addiction Reports. 2019;6(3):218-28. doi:10.1007/s40429-01900261-3.

43. Bourdier L, Orri M, Carre A, Gearhardt A, Romo L, Dantzer C, et al. Are emotionally driven and addictive-like eating behaviors the missing links between psychological distress and greater body weight? Appetite. 2018;120:536-46.

doi:10.1016/j.appet.2017.10.013.

44.Carter JC, Van Wijk M, Rowsell M. Symptoms of 'food addiction' in binge eating disorder using the Yale Food Addiction Scale version 2.0. Appetite. 2019;133:362-9. doi:10.1016/j.appet.2018.11.032.

45.Leigh SJ, Lee F, Morris MJ. Hyperpalatability and the Generation of Obesity: Roles of Environment, Stress Exposure and Individual Difference. Curr Obes Rep. 2018;7(1):6-18. doi:10.1007/s13679-018-0292-0.

46.Duffey KJ, Gordon-Larsen P, Jacobs DR, Jr., Williams OD, Popkin BM. Differential associations of fast food and restaurant food consumption with 3-y change in body mass index: the Coronary Artery Risk Development in Young Adults Study. Am J Clin Nutr. 2007;85(1):201-8. doi:10.1093/ajcn/85.1.201.

47.Pedram P, Sun G. Hormonal and dietary characteristics in obese human subjects with and without food addiction. Nutrients. 2015;7(1):223-38. doi:10.3390/nu7010223.

48.Darmon N, Drewnowski A. Does social class predict diet quality? Am J Clin Nutr. 2008;87(5):1107-17.

doi:10.1093/ajen/87.5.1107.

49.Burrows T, Kay-Lambkin F, Pursey K, Skinner J, Dayas C. Food addiction and associations with mental health symptoms: a systematic review with meta-analysis. J Hum Nutr Diet. 2018;31(4):544-72. doi:10.1111/jhn.12532.

50.Borisenkov MF, Tserne TA, Bakutova LA. Food addiction in Russian adolescents: Associations with age, sex, weight, and depression. Eur Eat Disord Rev. 2018;26(6):671-6. doi:10.1002/erv.2644.

Oct. 
51.Zhao G, Ford ES, Li C, Tsai J, Dhingra S, Balluz LS. Waist circumference, abdominal obesity, and depression among overweight and obese US adults: National Health and Nutrition Examination Survey 2005-2006. BMC Psychiatry. 2011;11(1):130. doi:10.1186/1471244X-11-130.

52.Canoy D, Wareham N, Luben R, Welch A, Bingham S, Day N, et al. Cigarette smoking and fat distribution in 21,828 British men and women: a population-based study. Obes Res. 2005;13(8):1466-75. doi:10.1038/oby.2005.177.

53.Broms U, Kaprio J, Hublin C, Partinen M, Madden PA, Koskenvuo M. Evening types are more often current smokers and nicotinedependent-a study of Finnish adult twins. Addiction. 2011;106(1):170-7. doi:10.1111/j.1360-0443.2010.03112.x.
54.Pepino MY, Finkbeiner S, Mennella JA. Similarities in food cravings and mood states between obese women and women who smoke tobacco. Obesity (Silver Spring). 2009;17(6):1158-63. doi:10.1038/oby.2009.46. 55.Chao AM, White MA, Grilo CM, Sinha R. Examining the effects of cigarette smoking on food cravings and intake, depressive symptoms, and stress. Eat Behav. 2017;24:615. doi:10.1016/j.eatbeh.2016.12.009.

56.Criscitelli K, Avena NM. The neurobiological and behavioral overlaps of nicotine and food addiction. Prev Med. 2016;92:82-9. doi:10.1016/j.ypmed.2016.08.009.

57.Zawertailo L, Attwells S, deRuiter WK, Le TL, Dawson D, Selby P. Food Addiction and Tobacco Use Disorder: Common Liability and Shared Mechanisms. Nutrients. 2020;12(12):3834. doi:10.3390/nu12123834. 